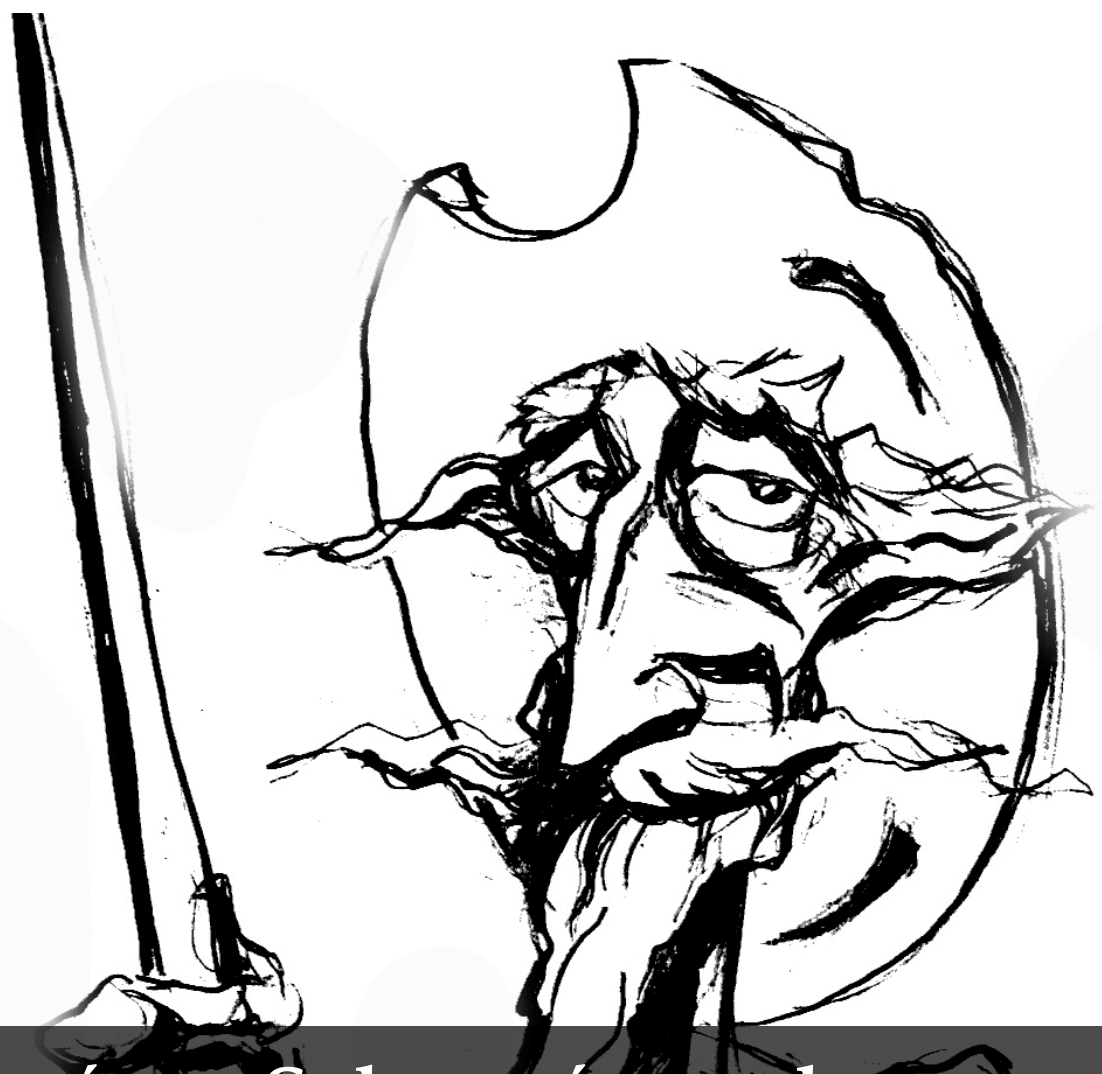

Autonomia y Soberanía en los usos de la noción Cde "pueblo": el cabildo y el gobernador, disputas políticas en torno del Estatuto Provisional en Tucumán en 1815

[Gabriela Lupiañez] 


\title{
Autonomía y Soberanía en los usos de la noción de "pueblo": el cabildo y el gobernador, disputas políticas en torno del Estatuto Provisional en Tucumán en 1815*
}

\section{Autonomy and sovereignty in the uses of the notion of "people": the cabildo and the governor, political disputes around the Provisional Statute in Tucumán in 1815}

\author{
GABRIELA PAULA LUPIAÑEZ
}

\section{Resumen}

En tiempos en que el gobierno central rioplatense expresaba la voluntad de asumir la titularidad de la soberanía, el pueblo de Tucumán se veía envuelto en disputas políticas en torno del juramento del Estatuto Provisional de 1815. La historiografía no indagó suficientemente en las motivaciones de los agentes involucrados. El análisis del conflicto a partir de los usos de la noción de "pueblo", permite sostener que la opción por el alineamiento con Buenos Aires desde las reformas borbónicas, no fue la única alternativa considerada por el pueblo de Tucumán.

Palabras claves: autonomía - soberanía pueblo/pueblos - juramento - Estatuto Provisional

\begin{abstract}
At a time when the central government of Rio de la Plata expressed the willingness to take ownership of sovereignty, people of Tucuman became involved in political disputes over the oath of the Provisional Statute of 1815. Historiography did not sufficiently investigate the motivations of the agents involved. The analysis of the conflict from the point of view of the uses of the notion of "people", allow to argue that the choice of alignment with Buenos Aires, although it was the dominant one since the Bourbon's reforms, was not the only alternative considered by the people of Tucuman.

Keywords: autonomy - sovereignty people/peoples - oath - Provisional Statute
\end{abstract}

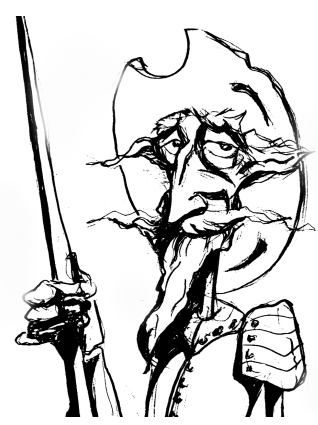

Recibido con pedido de publicación el 21 de diciembre de 2015

Aceptado para su publicación el 3 de mayo de 2016

Versión definitiva recibida el 6 de julio de 2016

Gabriela Paula Lupiañez, Universidad Nacional de Tucumán, Argentina; email: gabriela.lupianez@filo.unt.edu.ar; gabriela.lupianez@gmail.com

\footnotetext{
* Presenté una versión de este trabajo en el Congreso Internacional de Estudios Latinoamericanos de Postgrado / I Encuentro Nacional de Cátedras de Historia de América, Facultad de Filosofía y Letras - Universidad Nacional de Tucumán, Tafí del Valle (Tucumán), 12 a 14 de noviembre de 2015. Agradezco los comentarios de Valentina Ayrolo y de los evaluadores.
}

Esta obra se publica bajo licencia Creative Commons. Atribución-NoComercial-CompartirIgual 4.0 Internacional

Lupiañez, Gabriela Paula "Autonomía y Soberanía en los usos de la noción de 'pueblo': el cabildo y el gobernador, disputas políticas en torno del Estatuto Provisional en Tucumán en 1815”, Prohistoria, Año XIX, núm. 26, dic. 2016, pp. 27-52. 
"Mira por tu pueblo a quien Buenos Aires mira con especial benevolencia por la adhesión que le profesa y la juiciosidad con que se porta, no siguiendo el ejemplo de otros pueblos locos que respiran división y desunión de fuerzas cuando nunca debían de estar más unidos". ${ }^{1}$ Esta era la sentida recomendación de Fray Cayetano Rodríguez a su ex discípulo y cercano amigo, el cura vicario tucumano Agustín Molina, en un contexto en el que el gobierno central no controlaba el territorio rioplatense y un restaurado Fernando VII amenazaba aplastar la insurgencia americana.

Desde fines de 1814, el cabildo tucumano compartía su autoridad con un nuevo factor de poder de origen revolucionario, el gobernador de la nueva intendencia de Tucumán. Esto generó tensiones que trascendieron lo meramente coyuntural. Según señaló oportunamente Ramón Leoni Pinto, “Hacia 1815... el conflicto entre aquellas instituciones [gobernador y cabildo] sirvió para, finalmente, imponer el ideal revolucionario". ${ }^{2}$ Estas tensiones locales manifestadas en agentes (cabildo y gobernador), motivaciones (ideal revolucionario) y acciones (en torno de relaciones de poder), giraron en torno del "ideal revolucionario" de soberanía única. Idea estandarte de una facción con redes supralocales que trabajó para hacerse con la hegemonía hasta 1820 y que, en el caso tucumano, fue resistida por algunos miembros de la comunidad, que encontraban eco en el cabildo.

Mientras esto ocurría en la ciudad de Tucumán, varios pueblos rioplatenses reasumían la soberanía, desconociendo al gobierno central. Sin embargo, la rápida respuesta de un nuevo grupo encabezado por el cabildo porteño procuró una salida a la crisis con el nombramiento de autoridades provisorias junto a la promesa de un nuevo Congreso que dirimiera los destinos de los pueblos. Asimismo, creó una Junta de Observación que sancionó un “Estatuto Provisional para la dirección y administración del Estado" que demandó el reconocimiento del resto de los pueblos rioplatenses. ¿Qué cuestiones puso en discusión la demanda de juramento del Estatuto en el seno de la comunidad local?

Cabe recordar que el consentimiento de los pueblos, en tanto sujetos soberanos, fue clave para legitimar y legalizar los nuevos gobiernos surgidos al calor de la revolución. La demanda de consentimiento al Estatuto desató la competencia entre cabildo y gobernador, en el seno de la comunidad tucumana por definir quién era el portavoz legítimo del "pueblo". Estas tensiones repercutieron en la relación del "pueblo" de Tucumán con los gobiernos

\footnotetext{
${ }^{1}$ Carta de Cayetano Rodríguez a José Agustín Molina, Buenos Aires, 18 de julio de 1815, en RODRÍGUEZ, Fray Cayetano Correspondencia con el Doctor José Agustín Molina (1812-1820), Academia Nacional de la Historia, Buenos Aires, 2008, p. 137.

2 LEONI PINTO, Ramón Tucumán y la región noroeste. 1810-1825, Academia Nacional de la

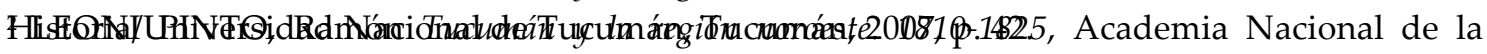
Historia/Universidad Nacional de Tucumán, Tucumán, 2007, p. 42.
} 
revolucionarios centrales. con quienes podía establecerse relaciones alternativas según las coyunturas. Así la "autonomía" tucumana podía, al menos en teoría, oscilar entre la adhesión a la política centralizadora de Buenos Aires, la autonomía frente a la capital porteña $\mathrm{u}$ otras ciudades pasando por la confederación hasta llegar a la independencia total. ${ }^{3}$

La historiografía refiere que el pueblo de Tucumán adhirió al Estatuto, ${ }^{4}$ sin más detalle. Más allá de Leoni Pinto, la historiografía que se ocupó del caso tucumano poco dice en torno de los conflictos de diversa intensidad que la política revolucionaria desató a nivel local y las alternativas de vínculo que proponían con los gobiernos revolucionarios de Buenos Aires. Es posible que en la disputa que replicaba a escala local la cuestión irresuelta de quién y dónde se ejercía el poder, el "pueblo" o los "pueblos", los contendientes apelaran a usos diversos de la noción de "pueblo" para legitimar su posición. Estos incluían modos alternativos de entender la relación entre el pueblo de Tucumán y el gobierno revolucionario. Así, la relación armónica entre autoridades centrales con sede en Buenos Aires y la ciudad tucumana descripta por la historiografía como una relación sin solución de continuidad desde tiempos de las reformas borbónicas, ${ }^{5}$ no fue la única alternativa discutida al interior de la ciudad devenida en capital de la provincia de Tucumán en la coyuntura de 1815.

En este escrito interesa identificar los usos de la noción de "pueblo" a partir de dichos y acciones de agentes de la elite local, principalmente el gobernador y el cabildo en relación con el juramento del Estatuto Provisional, así como de las alternativas autonómicas que manejó, entendiendo que palabras y prácticas se entrelazan. Se considera el "juramento", como sanción, ratificación o, en este caso particular, “acto jurídico que daba validez a una

\footnotetext{
3 CHIARAMONTE, José Carlos Ciudades, provincias, estados: orígenes de la Nación argentina (18001846), Ariel, Buenos Aires, 1997, p. 159.

4 ABBATE, Georgina; DAVIO, Marisa y ESPÍNDOLA, Alfredo "Revolución, guerra y representación política", en LÓPEZ, Cristina del Carmen (dir.) Orden y conflictos. Tucumán, de la colonia a la Organización Nacional, Prohistoria, Rosario, 2013, p. 87. ABBATE, Georgina; DAVIO, Marisa y ESPÍNDOLA, Alfredo "Revolución...", cit., pp. 57-111. PÁEZ DE LA TORRE, Carlos Historia de Tucumán, Buenos Aires, Plus Ultra, 1987, p. 229. TERNAVASIO, Marcela Gobernar la revolución. Poderes en disputa en el Río de la Plata, 1810-1816, Siglo XXI Editores, Buenos Aires, 2007, p. 173. BAZÁN, Osvaldo Raúl Historia del Noroeste Argentino, Buenos Aires, Plus Ultra, 1986, p. 169.

${ }^{5}$ GARCÍA, Irene La construcción del espacio político. Tucumán en la primera mitad del siglo XIX, Instituto de Historia y Pensamiento Argentino / Facultad de Filosofía y Letras -Universidad Nacional de Tucumán, Tucumán, 2003. TíO VALLEJO, Gabriela Antiguo Régimen y Liberalismo. Tucumán, 1770-1830, Col. Cuadernos Humanitas, Facultad de Filosofía y Letras - Universidad Nacional de Tucumán, Tucumán, 2001. LEONI PINTO, Ramón Tucumán y la región noroeste..., cit. LIZONDO BORDA, Manuel Historia de Tucumán (s. XIX), Universidad Nacional de Tucumán, Tucumán, 1948. ÁVILA, Julio P. La ciudad arribeña. Tucumán, 1810-1816. Reconstrucción histórica, Ediciones del Rectorado/Universidad Nacional de Tucumán, Tucumán, 2003.
} 
norma" ${ }^{\prime 6}$ y con ello expresión del consentimiento (o no) de la ciudad a una nueva relación de subordinación. En este sentido, se procura identificar quién es el agente que jura; ámbitos de expresión de ese sujeto; modos de ejercicio de la misma así como el sentido asignado a su acción o motivaciones.

Este capítulo se organiza en cinco partes. El primer apartado refiere brevemente a los usos historiográficos de las nociones de "pueblo" y "autonomía". El segundo remite al contexto inmediatamente previo a la sanción del Estatuto. Un tercer apartado se ocupa de los usos de la noción de "pueblo" en torno de la iniciativa capitular vinculada a la jura del Estatuto de 1815. El cuarto se centra en la respuesta del gobernador a dicha iniciativa así como los usos de la noción de "pueblo" invocados por su facción. Finalmente, se propone un balance en torno de las alternativas autonómicas contenidas en los diversos usos de la noción de "pueblo" por parte de la elite tucumana en tiempos de debate en torno del sujeto y sede soberanos.

\section{Los usos de la noción de "pueblo" y de "autonomía" en la historiografía}

La historiografía demostró la relevancia política de la noción de "pueblo" en relación con la retroversión de la soberanía en la crisis de la monarquía hispana. Precisamente porque supuso un cambio en los fundamentos del poder político. Sin embargo, el debate irresuelto para los años de los que se ocupa este escrito acerca de quién era el sujeto de la soberanía, "los pueblos", depositarios de una soberanía retrovertida, que con ello cobraron relevancia política inédita7 o "el pueblo", sede de una soberanía única, da cuenta de la plurivocidad de esta noción. En el ámbito hispanoamericano en general y en el rioplatense en particular, el concepto de "pueblo" fue estudiado en relación con la política revolucionaria en Buenos Aires como sujeto político en relación con la plebe urbana porteña. Pero también se lo estudió atendiendo a los mecanismos de participación en relación con las estrategias de acceso al poder de tendencias federales en el espacio de Buenos Aires. ${ }^{8}$ Por su parte, la historia conceptual dio

\footnotetext{
6 Antonio Annino lo define en relación con normas regias. ANNINO, Antonio "Imperio, constitución y diversidad en la América Hispana", en Nuevo Mundo. Mundos Nuevos, Debates, 2008 [en línea], p. 13. También LORENTE, Marta "La nación y las Españas", en CLAVERO, Bartolomé; PORTILLO, José María y LORENTE, Marta Pueblos, Nación y Constitución (en torno a 1812), Ikusager Ediciones, Vitoria-Gasteiz, 2004, pp. 101-142.

7 CHIARAMONTE, José Carlos Ciudades, provincias, estados..., cit. GUERRA, François-Xavier (coord.) Modernidad e independencias. Ensayos sobre las revoluciones hispánicas, MAPFRE/Fondo de Cultura Económica, México, 1992. ANNINO, Antonio "Soberanías en lucha", en ANNINO, Antonio y GUERRA, François-Xavier (coord.) Inventando la nación. Iberoamérica siglo XIX, Fondo de Cultura Económica, México, 2003.

${ }^{8}$ DI MEGLIO, Gabriel ;Viva el bajo pueblo! La plebe urbana de Buenos Aires y la política entre la Revolución de Mayo y el rosismo, Prometeo Libros, Buenos Aires, 2007. HERRERO, Fabián "¿La revolución dentro de la revolución? Algunas respuestas ideológicas de la elite revolucionaria", en HERRERO, Fabián (comp.) Revolución. Política e ideas en el Río de la Plata durante la década de
} 
cuenta de usos comunes, de la convivencia de nuevos y viejos sentidos en diversas modalidades en la larga duración. ${ }^{9}$

Para el caso tucumano, Julio P. Ávila entendió que entre 1810 y 1815 hubo una renovación de la vida cívica local que identifica con elecciones de representantes a instancias supralocales así como ceremonias y guerra. Identifica el periodo con un agente novedoso, el "pueblo" en las actividades mencionadas suponiendo individuos en igualdad de status jurídicos ejerciendo la soberanía popular. Este uso anacrónico de la noción de "pueblo" también se vincula a un marco de referencia estatal inexistente en la época que utilizan otros autores de referencia ineludible (que incluye al propio Leoni Pinto) a la hora de sumergirse en la historia de Tucumán. ${ }^{10}$

En los últimos lustros, una historiografía de formación académica con renovados enfoques y herramientas, se ocupó de iluminar aspectos vinculados con actividades de las que tomó parte el "pueblo". Lo hizo atendiendo al discurso político de la elite o "descubriendo" el surgimiento de un grupo intermedio de auxiliares del cabildo que, en tiempos revolucionarios, trabajó en la articulación de las elecciones. ${ }^{11}$ Otras actividades estudiadas fueron las elecciones, ${ }^{12}$ ceremonias $^{13}$ la participación popular en las milicias y otras formas

1810, Ediciones Cooperativas, Buenos Aires, 2005, pp. 101-124. HERRERO, Fabián Movimientos de Pueblo. La politica en Buenos Aires luego de 1810, Rosario, Prohistoria Ediciones, 2012.

9 SÁ E MELO FERREIRA, Fátima “Entre viejos y nuevos sentidos. 'Pueblo' y 'pueblos' en el mundo iberoamericano entre 1750 y 1850", en FERNÁNDEZ SEBASTIAN, Javier (dir.) Diccionario político y social del mundo iberoamericano, Fundación Carolina/Centro de Estudios Políticos y Constitucionales, Madrid, 2009, pp. 1117-1250. GOLDMAN, Noemí y DI MEGLIO, Gabriel "Pueblo/pueblos", en GOLDMAN, Noemí (ed.) Lenguaje y revolución. Conceptos políticos clave en el Río de la Plata, 1780-1850, Prometeo, Buenos Aires, pp. 131-144. ROLDÁN VERA, Eugenia “'Pueblo' y 'Pueblos' en México, 1750-1850: un ensayo de historia conceptual", en Araucaria. Revista Iberoamericana de Filosofía, Política y Humanidades, Año IX, núm. 17, Sevilla, Primer semestre de 2007, Monográfico 2: El léxico de la política: el laboratorio conceptual iberoamericano, 1750-1850.

10 ÁVILA, Julio P. La ciudad..., cit. LIZONDO BORDA, Manuel Historia de..., cit. PÁEZ DE LA TORRE, Carlos Historia de ..., cit. LEONI PINTO, Ramón Tucumán..., cit.

${ }_{11}$ TÍO VALLEJO, Gabriela, Antiguo Régimen..., cit. GARCÍA, Irene La construcción del espacio político. Tucumán en la primera mitad del siglo XIX, Instituto de Historia y Pensamiento Argentino/Facultad de Filosofía y Letras-Universidad Nacional de Tucumán, Tucumán, 2003.

12 TÍO VALLEJO, Gabriela La república extraordinaria. Tucumán en la primera mitad del s. XIX. Prohistoria, Rosario, 2012. ABBATE, Georgina "Representación y opinión en el cabildo de Tucumán (desde fines de la monarquía hasta los comienzos de la Revolución), en LÓPEZ, Cristina del Carmen (comp.) Identidad, representación y poder entre el Antiguo Régimen y la revolución. Tucumán, 1750-1850, Prohistoria, Rosario, 2009, pp. 141-156. SAVI, Mariana, Transformaciones en la representación política. Primera mitad del siglo XIX, Facultad de Filosofía y Letras - Universidad Nacional de Tucumán, Tucumán, diciembre de 2005 (tesina de grado inédita).

${ }^{13}$ WILDE, Ana Cristina "Representaciones de la política posrevolucionaria. Un acercamiento a la liturgia republicana (1810-1853)", en TÍO VALLEJO, Gabriela La república..., cit., pp. 79-146. CORREA, Silvina "Notas sobre representaciones, cultura política y ceremonias cívicas. 
de participación popular alternativas a las elecciones. ${ }^{14}$ También se dio cuenta de los sectores populares en perspectiva económica, atendiendo a la relación trabajo/ocio. ${ }^{15}$

Por otra parte, la cuestión de las relaciones entre los pueblos rioplatenses y las autonomías provinciales, fue largamente objeto de atención de una historiografía argentina que hizo un uso anacrónico de la noción de estadonacional. Hoy, la propia noción de "autonomía" es historizada a la vez que puesta a prueba en el análisis de casos, revisando los tradicionales argumentos sobre el federalismo/unitarismo e iluminando aspectos poco conocidos de las relaciones entre los pueblos rioplatenses. ${ }^{16}$ La adhesión tucumana a las políticas

Tucumán 1812-1820", en GARCÍA de SALTOR, Irene y LÓPEZ, Cristina del Carmen (comp.) Representaciones, sociedad y poder. Tucumán en la primera mitad del siglo XIX, Facultad de Filosofía y Letras - Universidad Nacional de Tucumán, Tucumán, 2005, pp. 325-341.

${ }^{14}$ BRAVO, María Celia "La configuración del poder en la provincia de Tucumán. Entre el asambleísmo y la institucionalización", en BONAUDO, Marta; REGUERA, Andrea y ZEBERIO, Blanca (coord.) Las escalas de la historia comparada. Dinámicas sociales, poderes políticos y sistemas jurídicos, Muiño y Dávila, Buenos Aires, 2008, pp. 125-152. MACÍAS, Flavia “Milicias y ciudadanos", en Junta de Estudios Históricos de Tucumán. Cuatro Bicentenarios. 1810, 1812, 1814, 1816, Centro Cultural Rougés/Fundación Miguel Lillo, Tucumán, 2012, pp. 49-72. MACÍAS, Flavia y PAROLO, María Paula "Guerra de independencia y reordenamiento social. La militarización en el norte argentino (primera mitad del siglo XIX)", en Iberoamericana, X, núm. 37, Berlín, 2010, pp. 19-38. DAVIO, Marisa "El proceso de militarización durante la Revolución. Tucumán, 1812-1819", en LÓPEZ, Cristina del Carmen (comp.) Identidad..., cit., pp. 83-102. DIACO, Karina “Tucumán y sus milicias, 1801-1812", en Tucumán y su Historia, Dpto. de Extensión, Facultad de Filosofía y Letras - Universidad Nacional de Tucumán, Tucumán, 2002, pp. 29-40.

15 PAROLO, María Paula "Ni suplicas, ni ruegos". Las estrategias de subsistencia de los sectores populares en Tucumán en la primera mitad del siglo XXI, Prohistoria, Rosario, 2008.

16 CHIARAMONTE, José Carlos Ciudades, provincias, estados..., cit. SEGRETI, Carlos S. A. Federalismo Rioplatense y Federalismo Argentino (El federalismo de Córdoba en los comienzos de la época independiente, 1810-1820), Centro de Estudios Históricos, Córdoba, 1995. HERRERO, Fabián Movimientos de Pueblo..., cit. HERRERO, Fabián "Una franja del discurso político posrevolucionario. Federalismos en Buenos Aires, 1810-1815", Quinto Sol, núm. 4, Santa Rosa de La Pampa, 2000, pp. 117-138; VERDÓ, Geneviève “¿Soberanía del pueblo o de los pueblos? La doble cara de la soberanía durante la revolución de la independencia (1810-1820)", en Andes. Antropología e Historia, núm. 13, Salta, 2002, pp. 145-169. VERDÓ, Geneviève “En vísperas del Congreso. La construcción de una identidad política en las Provincias Unidas del Río de la Plata, 1815-1816", en Anuario IEHS, núm. 21, Tandil, 2006, pp. 37-52. FREGA, Ana Pueblos y soberanía en la revolución artiguista. La región de Santo Domingo Soriano desde fines de la colonia a la ocupación portuguesa, Ediciones de la Banda Oriental, Montevideo, 2007, MARCHIONNI, Marcelo "Entre la guerra y la política. Las elites y los cabildos salto-jujeños en tiempos de Güemes", en BRAGONI, Beatriz y MATA, Sara (comps.) Entre la colonia y la república. Insurgencias, rebeliones y cultura política en América del Sur, Prometeo, Buenos Aires, 2008. AYROLO, Valentina "La ciudad cooptada. Refractarios y revolucionarios en Córdoba del Tucumán (1810-1816)", en Anuario IEHS, núm. 26, Tandil, 2011, pp. 11-29. AGÜERO, Alejandro "Autonomía por soberanía provincial. Historia de un desplazamiento conceptual en el federalismo argentino (1860-1930)", en AYROLO, Valentina y VERDO Geneviève Dossier. Las 
del gobierno revolucionario -contribuciones de guerra, selección de representantes a reuniones supralocales, juramento de autoridades, lenguaje revolucionario-, fueron oportunamente enfatizados tanto por los análisis de Leoni Pinto, Gabriela Tío Vallejo e Irene García de Saltor. Las autoras mencionadas consideran que mientras la ciudad tuvo calidad de subordinada trató de escapar de la influencia de Salta, la capital de la intendencia. Para ello apeló sistemáticamente a la autoridad virreinal en su rol de árbitro. Esta relación con los gobiernos ubicados en Buenos Aires, que reflejaba un comportamiento similar al de otras ciudades subordinadas, continuó sin solución de continuidad más allá de la crisis de la monarquía y la revolución. Tío Vallejo, desde una "historia social de las instituciones", considera que la "autonomía" de la ciudad se vio incrementada en términos de intensificación y extensión del poder capitular en su jurisdicción. El poder capitular creció entre fines de la colonia y los tiempos revolucionarios con la organización de elecciones y la formación de un grupo intermedio de agentes en relación con el control del acto electoral. Esta situación parece paralela al hecho de que "El liderazgo de Buenos Aires es una realidad incontestable para Tucumán por lo menos hasta 1819". ${ }^{17}$ Por su parte, García de Saltor en clave de historia política, entiende que la "autonomía" tuvo mucho que ver con una larga tradición de carencia de autoridades vinculadas al poder real en la ciudad tucumana. Estas propuestas priorizan el largo plazo por encima de las coyunturas de la soberanía dificultando la atención a los matices que estas ofrecen y la ciudad aparece antes como una escala de análisis conveniente que como un sujeto político central en tiempos de discusión sobre el sujeto y sede del poder.

\section{La creación de la nueva intendencia de Tucumán en el contexto de guerra en todos los frentes y la difícil relación de los pueblos con el poder central}

El 1ํ de diciembre de 1814 Bernabé Aráoz quedaba “posesionado y reconocido por tal Gobernador Intendente de esta Provincia del Tucumán, prometiendo obrar fiel y legalmente en el empleo que se le ha conferido", 18 ante el cabildo tucumano. Aráoz, Coronel del regimiento de Dragones de Milicias regladas de Tucumán y Coronel Mayor de los Ejércitos de la Patria, había sido nombrado para tal encargo en Buenos Aires el 11 de noviembre de 1814. La nueva provincia incluía, además de San Miguel de Tucumán como capital, a las ciudades de Santiago y Catamarca. La decisión del Director Supremo de crear la intendencia de Tucumán a partir de la división de la antigua intendencia de

Provincias antes de la Nación en Argentina. Entre la soberanía, la autonomía y la independencia, Programa interuniversitario de Historia Política, enero 2016, en línea.

17 TÍO VALLEJO, Gabriela, Antiguo Régimen..., cit., p. 216.

18 Acta Capitular del $1^{\circ}$ de diciembre de 1814, en Documentos Tucumanos. Actas del cabildo; Introducción y notas de Manuel Lizondo Borda, Tucumán, Universidad Nacional de Tucumán, 1939, I, pp. 230-231 (en adelante AC). 
Salta del Tucumán, databa del 8 de octubre de ese año. Fue la última intendencia en crearse dentro de un esquema de división de las antiguas unidades de origen borbónico que entre fines de 1813 y 1814, modificó la geografía política colonial. ${ }^{19}$ La tendencia a la creación de nuevas intendencias procuró por un lado, responder a la demanda de algunos pueblos por mayores márgenes de toma de decisiones pero también a las necesidades de la guerra y a la amenaza de líderes militares que cuestionaban decisiones del poder central. En el caso de la nueva provincia tucumana, la decisión procuraba mantener a raya al frente de guerra norte pero también a Martín Miguel de Güemes, enemistado con Rondeau, a cargo del Ejercito Auxiliar del Perú. ${ }^{20}$

Por primera vez, entonces, la ciudad de Tucumán era sede oficial del gobernador, nombrado por el poder revolucionario a la cabeza de una unidad administrativa de tradición borbónica. Con ella debió convivir el cabildo local, portavoz tradicional del pueblo, no siempre en los mejores términos. Aráoz era tucumano y miembro de una familia influyente. En este sentido, un gobernador tucumano para la provincia de Tucumán probablemente era una excepción en un horizonte de intendencias dominado por gobernadores-intendentes y tenientes de gobernador foráneos, nombrados por y responsables ante el gobierno central con sede en Buenos Aires. La carrera "pública" de Aráoz se había iniciado en las milicias locales. Con ellas marchó a socorrer a Buenos Aires durante la primera invasión inglesa. Ocupó cargos capitulares y en 1812, lideró la defensa de la ciudad frente al "ejército del virrey del Perú" junto a las tropas de Belgrano. Recomendado a Posadas por San Martín, Aráoz construía su liderazgo militar y político al calor de la revolución.

Pero si la creación de intendencias por parte del gobierno central tuvo por fin evitar pérdida de control sobre el territorio, esta situación no se sostuvo en el tiempo. Durante los primeros meses de 1815, el poder central fue desafiado desde diversos frentes y culminó con la caída del Director Supremo Carlos María de Alvear. Artigas avanzaba en su dominio del Litoral desde comienzos de año. El pueblo de Mendoza había rechazado la decisión de Alvear de despojar de la jefatura del ejército de los Andes a San Martín. Córdoba declaraba su "independencia" -breve pero decidida-, de la mano de los "Pueblos Libres" liderados por Artigas. Rondeau encabezaba un ejército en el Norte prácticamente autónomo cuya autoridad era cuestionada por Güemes, quien se hacía elegir gobernador en Salta. Incluso al interior del propio gobierno "alvearista" bonaerense se construía una oposición a la excluyente política del Director Supremo, dando pie a la progresiva conformación de una

${ }^{19}$ SEGRETI, Carlos S. A. Federalismo Rioplatense..., cit., pp. 74-76.

${ }^{20}$ MATA, Sara "'Güemes cual otro Artigas'. El Congreso de 1816 y la hegemonía porteña", en VII Reunión del Comité Académico de Historia, Regiones y Fronteras. 14, 15 y 16 de abril de 2016, Horco Molle/Tucumán (inédito). BAZÁN, Osvaldo Raúl Historia..., cit., pp. 169-170. Agradezco a Sara Mata el haberme facilitado la consulta de su trabajo. 
alternativa confederacionista que, sin embargo, no logró hacerse con el poder. ${ }^{21}$

Por un lado, la respuesta a la crisis por los pueblos fue la multiplicación de relaciones transversales entre ellos, sin que pasaran necesariamente por Buenos Aires. Esto pareció especialmente válido para las ciudades de Córdoba, Mendoza, Salta y Tucumán. Entre fines de marzo y comienzos de abril, Aráoz intercambiaba correspondencia con José Javier Díaz, gobernador de Córdoba y también con San Martín, gobernador de Cuyo. En la correspondencia daba señales de acuerdo con la iniciativa del gobernador de Córdoba de promover el liderazgo de Rondeau. ${ }^{22}$ Por el otro, al interior de las ciudades, los cabildos y gobernadores, elegidos o aprobados, por la comunidad local, asumieron un rol clave. ${ }^{23}$ De hecho, diversas autoridades nombradas por el gobierno central fueron reemplazadas por esos días por autoridades locales como el cabildo o asambleas representativas, apoyadas por el cabildo, en los pueblos de Córdoba, Salta y Santa Fe.

El 3 abril de 1815, un pronunciamiento militar en Fontezuelas, con apoyo de los ejércitos en el oeste y norte del territorio rioplatense bajo dominio revolucionario, desató una anunciada crisis política en los territorios rioplatenses. Días después, el cabildo porteño dispuso la deposición de quien había regido el ejecutivo desde enero de ese año, el joven Director Supremo Carlos de Alvear, así como la disolución de la Asamblea General Constituyente reunida desde 1813. En su reemplazo fue electo Director José Rondeau, quien estaba al mando del Ejército Auxiliar del Norte y el cargo fue interinamente ocupado por Ignacio Álvarez Thomas, líder del ejército rebelado en Fontezuelas. Por otra parte, se creó una Junta de Observación encargada de la convocatoria a un nuevo congreso. Dicha Junta dictó un "Estatuto Provisional para la dirección y administración del Estado" el 5 de mayo de 1815. La rápida reacción del nuevo grupo centralista que se hizo con el poder en Buenos Aires junto a la promesa de reunión de un congreso de los pueblos, permitió al gobernador tucumano alinearse rápidamente con esa facción. Por su parte, el cabildo local intentó realizar otro itinerario.

\section{El momento del cabildo}

Recibidas las novedades de Buenos Aires por medio de un oficio circular del

21 SEGRETI, Carlos S.A. Federalismo Rioplatense..., HERRERO, Fabián "Una franja...", cit. AYROLO, Valentina "La ciudad...", cit. VERDÓ, Geneviève, “Soberanía del pueblo...", cit. MARCHIONNI, Marcelo "Entre la guerra...", cit.

22 VERDÓ, Geneviève "En vísperas...", cit., p. 39.

${ }^{23}$ VERDÓ, Geneviève "El precio del poder: formas y usos políticos de la representación en la independencia argentina (1810-1821)", en GUERRA, François-Xavier "Dossier: La Independencia de la América Hispana", en Revista de Indias, LXII, núm. 225, Madrid, mayoagosto 2002, p. 397. 
Cabildo de la Capital de Buenos Aires del 21 de abril, el gobernador Bernabé Aráoz ofreció al gobierno central y a la prensa oficial una imagen que no dejaba lugar a dudas respecto de la aceptación de las novedades por parte del pueblo tucumano. En un oficio del 2 de mayo publicado por la "Gaceta de Buenos Aires" indicaba que "este Gobierno, todo el Pueblo, y sus respectivas corporaciones han ratificado tan acertada elección [de Rondeau y Álvarez Thomas] con públicos regocijos". ${ }^{24}$ El gobernador aludía así al "pueblo" en tanto comunidad local integrada por corporaciones sobre la que ejercía su autoridad. La ratificación de las nuevas autoridades del gobierno central rioplatense por parte de los pueblos venía a sumarse al esfuerzo por salvar de la acefalía a estos territorios, en los dichos del gobernador de Tucumán. El mismo 2 de mayo de 1815 el cabildo tucumano "aprobaba y ratificaba el nombramiento hecho [en José Rondeau como Director Supremo y en su suplente Ignacio Álvarez Thomas] sin perjuicio de los derechos del Pueblo que cuando lo permita el orden de actuales sucesos manifestará su aprobación con libertad y franqueza." ${ }^{25}$ En el mismo tono escueto, la institución capitular respondía a su par de Buenos Aires en relación al Estatuto Provisional recibido posteriormente. Se debía "oír al pueblo para que él mismo lo sancionara libremente bajo las modificaciones y reformas que estimara convenientes". ${ }^{26}$

La iniciativa capitular proponía el rechazo al "consentimiento automático" a las nuevas autoridades y al Estatuto. Una facción que encontraba eco en el cabildo tucumano pareció tomar la iniciativa y proponer un camino diferente al usual en su relación con el gobierno central, no solo por la decisión de consultar al "pueblo" sino por los efectos posibles de la misma. ${ }^{27}$ El cabildo

\footnotetext{
2424 de junio de 1815. Junta de Historia y Numismática Americana, Gaceta de Buenos Aires (18101821), Compañía Sudamericana de Billetes de Banco, 1912, Buenos Aires, IV, 1814-1816.

${ }^{25}$ Acta del 02 de mayo de 1815, en $A C$, p. 256.

26 "Oficio del Cabildo de Tucumán al de Buenos Aires", $1^{\circ}$ de junio de 1815, en CORREA LUNA, Carlos Antecedentes porteños del Congreso de Tucumán. (Prólogo a al Tomo VIII de los documentos para la Historia Argentina), Compañía Sud-Americana de Billetes de Banco, Buenos Aires, 1917, p. 51.

${ }^{27}$ LUPIAÑEZ, Gabriela Paula "Soberanía popular/soberanía de los pueblos. La disputa política en Tucumán y los usos de la noción de "pueblo", 1810-1815", en Seminario "El largo siglo XIX latinoamericano", ISES (Instituto Superior de Estudios Sociales) CONICET/UNT-Museo de la Casa Histórica, San Miguel de Tucumán, agosto de 2010 (inédito). LUPIAÑEZ, Gabriela Paula "Autogobierno de una ciudad secundaria del Virreinato del Río de la Plata en la crisis de la monarquía hispana. San Miguel de Tucumán, 1808-1810", en NÚÑEZ, Paula (comp.) Miradas transcordilleranas. Selección de trabajos del IX Congreso Argentino-Chileno de Estudios Históricos e Integración Cultural, CONICET/ Instituto de Investigaciones en Diversidad Cultural y procesos de cambio/ Universidad Nacional de Río Negro. Sede Andina, San Carlos de Bariloche, 2011, pp. 278-286, http://iidypca.homestead.com/PublicacionesIIDyPCa/Nunez/MIradas.pdf. LUPIAÑEZ, Gabriela Paula “Autonomía y 'nombramiento' de representantes a reuniones generales en tiempos de autonomismo en el Río de la Plata (1810-1811). La ciudad de San Miguel de Tucumán y su diputado a la Junta Grande", en Americania. Revista de Estudios Latinoamericanos,
} 
tucumano avanzaba en un camino desconocido que implicaba diversas alternativas: rechazarlo como lo hizo el cabildo de Mendoza (aunque de la mano de una Junta de Guerra); aprobarlo con modificaciones como propuso el cabildo de Salta o aprobarlo automáticamente como lo planteó en los dichos y, posteriormente, en los hechos el gobernador tucumano.

El 12 de junio de 1815, el cabildo definió el procedimiento a través del cual el pueblo tucumano se expresaría, fundamentando

"que habiendo recibido y visto el nuevo Estatuto provincial (sic) de cinco de Mayo formado en la Capital de Buenos Aires para el gobierno de las Provincias Unidas, después de examinado y consultado sobre la forma que se debe guardar para la sanción que se solicita, que todo se haga por el Pueblo reunido en ocho cuarteles y que en cada uno se elija por votación un diputado con suficientes y amplios poderes para que sancionen lo que sea conveniente, alteren y varíen lo que pueda ser perjudicial al Pueblo y ratifiquen la elección celebrada en Buenos Aires en la persona del Señor general Don José Rondeau para Director Supremo del Estado y para suplente suyo en el Señor Coronel Mayor don Ignacio Álvarez y cuanto sea más conveniente a la unión y defensa de la causa común" 28

La selección de quienes conformarían el cuerpo se haría a través del procedimiento electoral. De este modo, el cabildo tucumano decidía formar una junta que estudiara el Estatuto a la vez que aclaraba que esto no era óbice para mantener lazos de unión con el resto de los pueblos en general, y el gobierno central en particular. No era la primera vez que el cabildo echaba mano al recurso de elecciones indirectas con el fin de conformar un cuerpo. La primera vez había sido en relación con la selección de socios para la junta subalterna en 1811. Pero en esa ocasión como en el resto, y a diferencia de esta, el cabildo había acatado normativa enviada por el gobierno central..$^{29}$

La decisión de dar el consentimiento (o no) al Estatuto surgiría de la discusión respecto de qué intereses locales se veían afectados por la normativa emitida por el gobierno revolucionario de manera inconsulta. El cabildo tucumano se mostró así atento a "abrir el juego". Por un lado, convocó a la comunidad a través de sus representantes para tomar decisiones de modo que

Nueva Época. Número Especial. El Proceso de Independencia en el Río de la Plata, Sevilla, Mayo 2015, https://www.upo.es/revistas/index.php/americania/issue/view/89.

${ }^{28}$ Acta del 12 de junio de 1815 , en $A C . .$, , cit., pp.266-267.

29 Tío Vallejo considera que entre 1815 y 1816 se pasó de procesos electorales "controlado(s) de principio a fin por el cabildo a la autonomía de las juntas electorales". TÍO VALLEJO, Gabriela Antiguo Régimen..., cit., p. 233. Ver también ABBATE, Georgina; DAVIO, Marisa y ESPINDOLA, Alfredo “Revolución, guerra y representación política ..., cit., p. 72. 
el "pueblo...[pueda] exponer sus derechos y representarlos"..$^{30}$ Por el otro, puso a disposición pública un ejemplar del Estatuto para su consulta, habilitando de esta manera la discusión pública. De hecho, los elegidos eran investidos de un poder amplio puesto que no tenían un mandato preciso o puntual respecto de qué hacer con el Estatuto. En relación con la decisión de discutir el Estatuto con una representación ampliada frente a lo que pudiera ser un "cabildo abierto", replicaba lo realizado poco antes en Salta. En esa ciudad, nueve representantes nombrados electoralmente habían conformado junto al cabildo una reunión que propuso modificaciones al Estatuto (aunque finalmente lo juró en julio de ese año). ${ }^{31}$ Aunque, también es cierto que la opción por elecciones indirectas permitía al cabildo canalizar la participación "popular" minimizando los posibles brotes de violencia. La institución capitular recurría así a una atribución desarrollada al calor de la revolución, que era confirmada por el Estatuto en cuestión, la que asignaba al cabildo la creación de padrones y con ello la definición del universo electoral. ${ }^{32}$

El 22 de junio se realizaron elecciones para nombrar diputados. A diferencia de lo propuesto por el Estatuto, la ciudad se dividió en ocho cuarteles, como había sucedido en la elección de diciembre de 1812 a diputados a la Asamblea General Constituyente, según lo establecía la Circular del 24 de octubre enviada por el II Triunvirato. Cada uno de esos cuarteles fue presidido por un sujeto capitular. Si bien es cierto que la elección pareció desarrollarse sin inconvenientes, la sola mención respecto de que los presidentes de mesa tenían "voto y jurisdicción para conservar el orden según la instrucción particular que se dará oportunamente para precaver acciones y reprobadas solicitudes" 33 hace sospechar que los ánimos estuvieron caldeados en esos días. ${ }^{34}$ Otra diferencia con el Estatuto fue la cuestión del modo de hacer efectiva la participación de los hasta hacia poco "habitantes" rurales, devenidos "ciudadanos" con los derechos

\footnotetext{
${ }^{30}$ Acta del 14 de mayo de 1815, en $A C \ldots$, cit., p. 259. Es probable que en la copia edita hubiera un error en el mes que se consigna. El Estatuto había salido a la luz el 5 de mayo de 1815. Resulta muy poco probable que el cabildo tucumano estuviera poniendo a disposición pública un ejemplar apenas nueve días después y sin antes haber sesionado. El acta que aquí aparece citada con fecha 14 de mayo seguramente corresponde al 14 de junio pues alude a los acuerdos del "12 del corriente", acuerdos que sí hubo en relación con el Estatuto, el 12 de junio de 1815.

${ }^{31}$ Reunión realizada el 10 de mayo de 1815, donde efectivamente se cuestionaron algunos puntos del Estatuto. MARCHIONNI, Marcelo “Entre la guerra ..., cit., pp. 225-226.

32 CHIARAMONTE, José Carlos con colaboración de TERNAVASIO, Marcela y HERRERO, Fabián "Vieja y nueva representación: los procesos electorales en Buenos Aires, 1810-1820", en ANNINO, Antonio (coord.) Historia de las elecciones en Iberoamérica. Siglo XIX, Fondo de Cultura Económica, Buenos Aires, 1995, pp. 19-63.

${ }^{33}$ Acta del 14 de mayo de 1815, en AC..., cit., p. 259.

${ }^{34}$ En tanto, el único inconveniente registrado en los documentos disponibles que, en principio, podría calificarse de "operativo" fue la ausencia injustificada de un capitular, el alguacil mayor Pedro Celestino Liendo. Fue reemplazado por el alcalde de primer voto del año anterior, Francisco Solano Cainzo, domiciliado en el mismo cuartel que el ausente. Acta del 22 de junio de 1815, en $A C . .$. , cit., pp. 267-268.
} 
y las obligaciones correspondientes. El cabildo fundamentó el modo de dar participación al ámbito rural, tradicionalmente subordinado a la ciudad y sin participación en las decisiones tomadas en esta justificando que,

"Y por cuanto la campaña por escasez de sujetos no admite la excusación de esta solemnidad, se pasaran oficios a los Alcaldes de curato para que por bando citen y emplacen a todos los vecinos que deban concurrir a la elección de los ocho Diputados con la facultad de incorporarse a los cuarteles que quieran a excepción de los que en ellos tengan raíces porque en este caso deberá seguir el vecindario de sus poblaciones y se señala el día veintidós del corriente"35

Si bien la participación rural no se realizaba de acuerdo a lo que proponía el reglamento de la Junta de Observación, el cabildo no había actuado fuera de la norma pero tampoco fuera de la tradicional relación jerárquica entre ciudad y campo. En primer lugar, porque el sentido de la elección era evaluar la validez del Estatuto en una reunión conjunta de capitulares y representantes de la comunidad local. En segundo lugar, porque el mismo Estatuto preveía en el

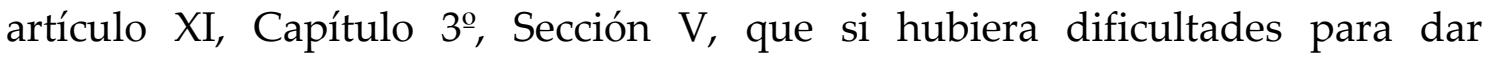
participación al ámbito rural del modo previsto, podía arbitrarse localmente el mejor modo de convocarlo. Y el cabildo tucumano había decidido incluir a "la campaña por escases de sujetos" a participar del acto electoral en la ciudad. Es difícil creer que la población rural tucumana fuera escasa. San Miguel de Tucumán, como en general todas las ciudades occidentales de la época preindustrial, debía tener una población rural sensiblemente mayor que la urbana. El territorio tucumano habría sido de los más densamente poblados del Río de la Plata. Los cálculos para la época proponen unos 4000 habitantes para la ciudad, a los que se le sumarían unos 16000 de su jurisdicción de campaña, es decir cerca de 20000 individuos. ${ }^{36}$ Por ello es dable inferir que los "sujetos escasos" a los que alude el documento eran aquellos de "calidad social",

\footnotetext{
${ }^{35}$ Acta del 12 de junio de 1815, en AC..., cit., pp. 266-267.

36 PAROLO, María Paula Estructura socio ocupacional y sectores populares en Tucumán. Primera mitad del siglo XIX, Tesis doctoral inédita, Facultad de Filosofía y Letras -Universidad Nacional de Tucumán, Tucumán, 2003. PUCCI, Roberto "La población y el auge azucarero en Tucumán", en Breves contribuciones del Instituto de Estudios Geográficos, núm. 7, Tucumán, 1992, p. 10. GIL MONTERO, Raquel Familia Campesina Andina. Entre la colonia y el nuevo estado independiente en formación, Tesis doctoral inédita, Facultad de Filosofía y Humanidades - Universidad Nacional de Córdoba, Córdoba, 1999, Vol. 1, p. 193. ARÁOZ, María Florencia “Evolución Demográfica de Tucumán a través de sus censos 1810-1869", en Revista de la Junta de Estudios Históricos, núm. 7, Tucumán, 1995, pp. 11-33. ARÁOZ, María Florencia “Evolución Demográfica de Tucumán a través de sus censos 1810-1869 (II)", en Revista de la Junta de Estudios Históricos, núm. 8, Tucumán, 1996, pp. 11-27.
} 
"vecinos" 37 en sentido tradicional, y no los nuevos "ciudadanos" partícipes de la soberanía en igualdad de status civil.

Con todo, los esfuerzos capitulares estuvieron concentrados en atraer votos de la campaña. Incluso, días después, convocó por medio del cabildo, a la reunión de habitantes del ámbito rural para "hacer la elección" 38 (aunque ya habían sido electos los diputados por la ciudad) en una acción que recordaba lo ocurrido en diciembre de 1812. En esa oportunidad, por iniciativa del electo diputado a la Asamblea General Constituyente, Nicolás Laguna, el cabildo ordenó a sus alcaldes de hermandad que "siendo regular que lleven al investidura de la voluntad general,... participamos a $\mathrm{Ud}$. que convocando a los habitantes de su distrito, requiera y reciba de ellos su libre consentimiento". ${ }^{39}$ Esa voluntad se plasmó concretamente en la aclamación de algunos habitantes rurales a una decisión previamente tomada en la ciudad donde se habían practicado elecciones indirectas, reproduciendo una relación jerárquica entre ciudad y "campaña" a la vez que corporativa.

Tío Vallejo entendió la aludida convocatoria del cabildo tucumano de 1812 como un ejemplo de la temprana participación de la campaña en elecciones, adelantándose a lo planteado por el Estatuto de 1815. E incluso insertó este acontecimiento en una tendencia de larga duración de continuidad ciudad-campo en Tucumán, a partir del señalamiento del rol de los jueces pedáneos como "representantes de sus partidos" a fines del siglo XVIII y figuras que adquieren nuevas funciones en relación con la organización de las elecciones con la revolución.

El señalamiento que aquí se hace en relación con lo acontecido en 1812 es que la calidad de la participación del ámbito rural y del urbano eran diferentes. Esas diferencias sostendrían la subordinación de la campaña a la ciudad y se mantendrían más allá de las relevantes novedades impulsadas por el Estatuto en relación con la soberanía. El Estatuto de 1815 estableció que "cada ciudadano es miembro de la soberanía del Pueblo", ${ }^{40}$ convirtiendo a parte de los habitantes (urbanos o rurales) de los "pueblos", comunidades políticas de naturaleza corporativa-territorial, en ciudadanos en igualdad de status legal. ${ }^{41}$ En la

37 Un estudio sumamente útil a la hora de intentar comprender el recorrido de la voz "Ciudadano/vecino" lo ofrece CANSANELLO, Oreste "Ciudadano/vecino", en GOLDMAN, Noemí (ed.) Lenguaje..., cit., pp. 19-34.

38 Acta del 22 de junio de 1815, en AC..., cit., p. 266. Domingo García, alcalde de 1er voto al alcalde de la Hermandad de los Juarez, Tucumán, 24 de junio de 1815, en Archivo General de la Nación, División Gobierno, Gobierno de Tucumán, 1815, Sala X. 5-10-3.

${ }^{39}$ Oficio del Alcalde ordinario Pedro Bernabé Gramajo al comisionado de Trancas, Tucumán, 10 de diciembre de 1812, en AHT. SA..., cit., fs. 373-375.

${ }^{40}$ Estatuto Provisional para la dirección y administración del Estado dado por la Junta de Observación, 5 de mayo de 1815, Sección Primera, Cap. IV.

${ }^{41}$ TÍO VALLEJO, Gabriela Antiguo Régimen..., cit., especialmente pp. 215 y 234. LUPIAÑEZ, Gabriela Paula “Soberanía popular/soberanía de los pueblos. La disputa política en Tucumán y 
práctica, esa igualación legal no se reflejaría en una amplia participación en la selección de autoridades por medio de elecciones indirectas. Fuera por un acto consciente de superioridad por parte del cabildo o simplemente expresión de las posibilidades al alcance dadas las distancias, los tiempos y la información de los habitantes de la campaña en relación con los procesos electorales, como quedó demostrado no solo en lo acontecido en 1812, sino también en la convocatoria capitular de la campaña en 1815 y la del gobernador.

En tanto, en la ciudad resultaron nombrados el Dr. Manuel Bazán, el Dr. Manuel Ledesma, José Manuel Terán, (José) Tomás Alurralde y Clemente Zavaleta. ${ }^{42}$ También habrían sido electos diputados el Dr. Nicolás Laguna y el Dr. (José) Agustín Molina, cura vicario foráneo hermano del diputado a la Junta Grande por Tucumán, amigo de fray Cayetano Rodríguez y prosecretario en el congreso reunido en Tucumán en $1816 .{ }^{43} \mathrm{El}$ Gobernador Intendente no asistió a la reunión "para tratar y acordar sobre la sanción del nuevo Estatuto" por encontrarse camino a su estancia, según los capitulares. ${ }^{44}$ La versión de Bernabé Aráoz fue que no había sido informado sobre dicha reunión. El mismo día de la elección Aráoz se quejaba por lo inconsulto de la actuación capitular y señalaba al cabildo que era la autoridad gubernativa, quien debía liderar la iniciativa de sanción (descartando de plano la discusión) del Estatuto,

"Hasta aquí se ha mantenido así esa Municipalidad Ilustre, como este Gobierno en la posesión pacífica de la jurisdicción...[y] autoridad, que les condecora, su honrado y sujeto vecindario, no ha desconocido hasta ahora los superiores respetos que vinculan su obediencia; tan solo el Magistrado celebra acuerdos, convoca a la ciudadanía, delibera públicamente gestiones [¿destinadas?] al bien general, desentendiéndose de quien como su cabeza debía precederles y [sobre ¿s?iendo?] al menos de instruirla oficialmente sobre el interesante oficio de sus determinaciones con arreglo a las legales disposiciones, que

\footnotetext{
los usos de la noción de "pueblo" (1810-1815)", en Seminario El largo siglo XIX, Museo Casa de la Independencia-ISES/CONICET, Tucumán, 2010. LUPIAÑEZ, Gabriela Paula "Usos de la noción de "pueblo" en tiempos del Congreso General Constituyente. San Miguel de Tucumán, 1816", en La independencia en Tucumán, su historia y su celebración. Lenguajes, prácticas políticas en una ciudad en guerra, Universidad Santo Tomás de Aquino, San Miguel de Tucumán, en prensa.

${ }^{42}$ Lamentablemente no hay información respecto de quiénes y cuántos votaron puesto que las actas electorales no fueron encontradas aún entre los documentos relevados en el Archivo Histórico de Tucumán ni en el Archivo General de la Nación. Acta del 22 de junio de 1815, en $A C$, pp. 268-269.

${ }^{43}$ Estos últimos no contaban entre los enumerados como electos diputados en el acta pero sí entre los firmantes que eran los capitulares junto a los diputados electos. Acta del 22 de junio de 1815, en $A C . .$. , cit., pp. 268-269.

${ }^{44}$ Acta del 12 de junio de 1815, en AC..., cit., p. 266.
} 
aun ejecutan y obligan. Con respecto a estos estrechos deberes es, que el Supremo Gobierno Provisorio con fecha 17 de mayo me recomienda especialmente coopere con el mayor esfuerzo al ejercicio libre de los sufragios, que deben dictar la sanción del Estatuto. Mal podría este gobierno desempeñar esta confianza, cuando le niegan los indispensables medios de ejecutarla. En esta virtud espera este gobierno, que VS le instruya como corresponde en el fin y objeto de las públicas providencias que ha librado del... 12 del presente, para su inteligencia". ${ }^{45}$

A pesar de la crítica a la iniciativa capitular, el gobernador dio su “consentimiento y aprobación" al nombramiento de diputados. Aunque puso objeciones. La primera fue el nombre del sargento mayor graduado Alurralde, ayudante de plaza. La segunda fue que su aprobación era realizada "sin perjuicio asimismo de los derechos que pertenecen a los vecinos de la jurisdicción, que no han concurrido." 46 Esto es, el gobernador, se erigía en vocero no ya del gobierno revolucionario sino de la fracción de la comunidad que entendía no había tenido parte en la elección, los habitantes de la campaña.

\section{El momento del gobernador}

El 20 de junio el gobernador Aráoz ordenaba al ayudante mayor de armas de Tucumán, Tomás Alurralde, que saliera de la ciudad con rumbo a la villa de Trancas donde recibiría órdenes. Alurralde se excusó del encargo. Dos días después, el gobernador le iniciaba sumario por solicitar sufragios a los "ciudadanos" para ser nombrado elector. ${ }^{47}$ Ese mismo día, mientras en la ciudad se realizaban los comicios para conformar la junta que trataría sobre el Estatuto, "vecinos" (sic) de la campaña dirigían una representación al Director Supremo suplicando se conservara como gobernador a Aráoz ante los rumores de su deposición. Firmaban el petitorio varias personas con cargos militares. Aráoz, por su parte, se dirigía reservadamente al Director Supremo, denunciando que "ocho diputados nombrados por el pueblo para reconocer el Estatuto se dirigen al proyecto de constituirse soberanos independientes de esta capital". ${ }^{48} \mathrm{La}$ acusación expresaba los temores reales o imaginarios del

\footnotetext{
4522 de junio de 1815, Archivo Histórico de Tucumán, Sección Administrativa, Vol. 24, fj. 155-156. ${ }^{46}$ Acta del 21 de junio de 1815, en AC..., cit., pp. 267-268.

${ }_{47}$ El gobernador Aráoz al ayudante de Plaza José Tomas Alurralde, Tucumán 20 de junio; Alurralde al gobernador, Tucumán 20 de junio; Sumario a José Tomas Alurralde, Tucumán 22 de junio, en Archivo General de la Nación, División Gobierno, Gobierno de Tucumán, 1815, Sala X. 5-10-3.

${ }^{48}$ Representación de varios vecinos al Director Supremo, 22 de junio; Domingo García al alcalde de Los Juárez; El gobernador Aráoz a Director Supremo, 24 de junio en Archivo General de la Nación, División Gobierno, Gobierno de Tucumán, 1815, Sala X. 5-10-3.
} 
gobernador. Aráoz llevaba tan solo siete meses en el gobierno de una nueva provincia creada por un poder central que no se había recuperado del todo de una crisis de autoridad profunda. Asimismo, a sus espaldas, Aráoz tenía la amenaza del gobernador de Salta quien, enfrentado con el Director Supremo titular y jefe del Ejército Auxiliar del Perú, procuraba construir su propio espacio de poder. A esto se sumaba la competencia de una facción vinculada al cabildo tucumano al interior de la ciudad capital.

Aráoz no participó de la reunión a la que había sido invitado el cabildo por estar en la "campaña" reuniendo adeptos. El 30 de junio de 1815, una reunión en las afueras de la ciudad, revocó las decisiones tomadas por el cabildo local, clausurando la discusión respecto del Estatuto. ${ }^{49}$ Esta no se realizó en la plaza, lugar central de toda urbanización que en los territorios americanos bajo dominio del rey de España se preciara de ciudad y por ello de pública y masiva concurrencia, sino en un sitio con fuertes connotaciones simbólicas, el "Campo de Honor", según rezaba el acta, sitio donde se había desarrollado el episodio central de la victoria del 24 de septiembre de 1812 ante el "ejército del virrey del Perú". Acontecimiento decisivo en la definición de la adhesión de los notables locales a la "revolución". ${ }^{50} \mathrm{Al}$ momento de convertirse en escenario de la victoria militar patriota, ese espacio despejado había sido nombrado como Campo de las Carreras por el uso que le daba la población. En 1814, durante su breve estancia en Tucumán, San Martín ordenó edificar allí una construcción militar que fue popularmente denominada "Ciudadela", ${ }^{11}$ dándole nombre a uno de los actuales barrios de la ciudad de San Miguel de Tucumán.

En la misma se encontraban "Congregados los habitantes de su Campaña [de Tucumán] que componen seis partidos e incorporándose a nosotros una parte considerable y sana de la Ciudad". ${ }^{52}$ La mayoría de los presentes en el sitio eran milicianos de zonas rurales. Se sabe que el número de enrolados en las milicias fue alto durante toda la década revolucionaria. Según el cálculo de fuerzas milicianas realizado por Bernabé Aráoz, “existían 1725 individuos

\footnotetext{
${ }^{49}$ La historiografía que estudió el acontecimiento atendió diversas dimensiones. A saber: como expresión de una conciencia soberana; en relación con la elección de diputados al Congreso; poniendo de relieve las formas de la representación política. Sin embargo, no lo han visto en clave de rivalidad entre cabildo y el gobernador en tanto poderes en disputa por convertirse en detentadores exclusivos de la soberanía popular, conllevando diversas alternativas de relación con el poder central en el contexto abierto por el Estatuto de 1815. LIZONDO BORDA, Manuel, Historia..., cit., p. 21. TÍO VALLEJO, Gabriela Antiguo Régimen ..., cit., pp. 237-239. ABBATE, Georgina; DAVIO, Marisa y ESPÍNDOLA, Alfredo “Revolución, guerra...", cit., pp. 86-90.

${ }^{50}$ GARCÍA, Irene La construcción del..., cit. LUPIAÑEZ, Gabriela Paula, "La batalla de Tucumán. Autogobierno y guerra en San Miguel de Tucumán en tiempos de soberanía retrovertida en depósito. El año de 1812", en Actas XII Jornadas de Investigación y Docencia de la Escuela de Historia, Universidad Nacional de Salta, Salta, 5 - 7 de diciembre de 2011.

${ }^{51}$ Apelativo con que Cayetano Aráoz presenta el acta original al cabildo. Acta del 30 de junio de 1815, en $A C . . .$, cit., pp. 270-274.

${ }^{52}$ Acta del 30 de junio de1815, en $A C$..., cit., p. 270.
} 
distribuidos en forma equitativa en las localidades de Río Seco, Nogales y Timbó, potrero Grande, Simoca, ciudad capital, Chicligasta, Monteros, Garcias, Burruyacu, Costillas, Río Chico, Juárez, Ticucho, Lules y Río Grande". ${ }^{53}$ Incluso pudieron llegar a alrededor de 3000. ${ }^{54}$ Las firmas recogidas sumaban alrededor de 167, cifra reducida respecto de las más de 4000 almas que decía el acta haber reunido. Esta última cifra era equivalente a la población total urbana en el momento. Muchas de las firmas correspondían a los jefes militares que estampaban su rúbrica en nombre propio y en el de sus subordinados del mismo modo que lo hicieron de los curas de los partidos de campaña de Los Juárez (hoy departamento de Leales), Burruyacu y Trancas. Otra estimación evaluaba la cantidad de los presentes en unos "500 a 1000 hombres todos armados". ${ }^{55}$ Si bien en este cálculo el número era sensiblemente menor, no dejaba de representar una cifra respetable. La condición militar de los presentes no puede dejar de relacionarse con la figura del gobernador y los títulos militares que ostentaba.

Entre los notables que encabezaban con su firma el acta por la "parte sana" figuraban el cura de la catedral local Pedro Miguel Aráoz y Cayetano Aráoz, capitular en diversas ocasiones. Ambos eran parientes cercanos del gobernador. ${ }^{56}$ Otro de los firmantes del acta era Pedro José Velarde, cuñado del gobernador y diputado de comercio. ${ }^{57}$ Había sido capitular y miembro del Tribunal de Concordia en 1812.58 También era Aráoz el cura de Trancas, Francisco Borja. Por otra parte, dentro de esta facción aparecían miembros de un sector social intermedio como el Alcalde de la Hermandad, Bernardino de Medina o los jefes militares con diversa graduación (capitán comandante, tenientes, sargentos).

Semejante congregación de personas fue justificada en términos de la defensa de los "sagrados derechos de todo ciudadano" frente a "un corto número de individuos facciosos [que] perturban la inalterable quietud" de los tucumanos, aludiendo a los ocho miembros electos el 22 de junio. En el acta se nombraba al "ciudadano" en el sentido dado por el Estatuto -"cada ciudadano es miembro de la Soberanía del Pueblo" y "En esta virtud tiene voto activo y

53 Aunque la autora no indica año, es probable que fuera 1815. Bernabé Aráoz al Poder Ejecutivo. Citado por DAVIO, Marisa "El proceso de militarización durante la Revolución. Tucumán 1812-1819", en LÓPEZ, Cristina del Carmen (comp.) Identidad..., cit., p. 94.

${ }^{54}$ MACÍAS, Flavia "Ciudadanos..., cit., p. 7.

55 Nicolás Laguna al Director Supremo, Tucumán 3 de julio de 1815. Citado por BAZÁN, Osvaldo Raúl Historia..., cit., p. 171.

${ }^{56}$ AVILA, Julio La ciudad arribeña..., cit., p. 66. CLESSI, María del Carmen "Autoridades del cabildo de Tucumán. Periodo independiente", en Actas del Primer Congreso de Historia Argentina y Regional, Buenos Aires, Academia Nacional de la Historia, 1971. Citada en LEONI PINTO, Ramón Tucumán ..., cit., p. 130.

${ }^{57}$ ÁVILA, Julio La ciudad..., cit., p. 68.

${ }^{58}$ LEONI PINTO, Ramón Tucumán..., cit., p. 130. 
pasivo",- 59 ergo, en el sentido de partícipe de una concepción de la soberanía única. En este esquema, el número de 4000 participantes tenía peso propio. La cantidad legitimaba el acto. Sin embargo, la notabilidad venía a complementar la fuerza del número y la velada amenaza a las armas con la calidad de sus participantes, dándole un fundamento tradicional a este nuevo modo de expresión política que echaba por tierra la exclusividad de la voz capitular en la representación del "pueblo". Un "pueblo" que debía ser visibilizado como capaz de iniciativa para torcer una decisión capitular. Pero, en definitiva, daba cuenta de una red familiar cuyos integrantes eran miembros de corporaciones militares, clericales y administrativas. De este modo, el tipo de lazo político recreado era tradicional y poco tenía que ver, en este sentido, con el espíritu del Estatuto que venían a ratificar.

La asamblea reafirmó los vínculos con Buenos Aires en coincidencia con la posición del gobernador. También anuló la elección de representantes o "diputados" del 22 de junio refiriendo vicios tales como la solicitud de sufragios y la deficiente participación de los habitantes rurales. ${ }^{60} \mathrm{El}$ argumento para la anulación de lo realizado el 22 de junio fue la infracción del Estatuto, sin reconocer que el objeto de esa elección era precisamente designar una junta que discutiera la normativa enviada por el gobierno central y su ratificación, modificación o rechazo. ${ }^{61}$ Asimismo, alterando también el procedimiento señalado por el Estatuto y "para evitar nuevas reuniones siempre peligrosas y perjudiciales", los participantes de la asamblea decidieron, en el mismo acto, "proceder al nombramiento de tres Diputados que representen en el próximo augusto Congreso la Capital de Tucumán y su jurisdicción" 62 de la siguiente manera:

“Todo lo que después de meditado y examinado con
reflexión y con la madurez que demanda el imperio de las
circunstancias, se procedió a votación de la cual resultó que
todos los concurrentes de común sentir dijeron que se
conformaban con la mayor complacencia y libertad en
adherir a los seis capítulos propuestos ... y en cuanto al
último artículo resultaron canónicamente electos y por
publica acta... de más de cuatro mil hombres para
diputados por la capital y su campaña en el próximo

59 "Prerrogativas del Ciudadano", Estatuto provisional para la dirección y administración del Estado, dado por la Junta de Observación (05 de mayo de 1815), Sección I, Capítulo IV.

${ }^{60}$ Acta del 30 de junio, 1815, en AC..., cit., p. 270.

${ }^{61}$ Además de haber incurrido en actos de soborno, se observaba la no participación de la campaña según las previsiones del Estatuto. Pero según las actas capitulares había habido individuos de la campaña en las mesas de la capital por insistencia capitular. Acta del 22 de junio de 1815, en $A C . .$. , cit., p. 266.

${ }^{62}$ Acta del 22 de junio de 1815, en AC..., cit., p. 266. 
congreso general a que se invita, los Señores Doctores Don Pedro Miguel Aráoz, Don José Agustín Molina y Don Juan Bautista Paz a quienes conferimos libre y espontáneamente todo nuestro poder amplio, y cual se requiere para que representen nuestros derechos en el congreso General"63

Los diputados electos eran los doctores Pedro Miguel Aráoz, José Agustín Molina y Juan Bautista Paz. Este último ocupó diversos cargos capitulares, entre ellos el de alcalde de primer voto en 1813. Fue asesor del cabildo entre 1811 y 1814 y, junto a Cayetano Aráoz, miembro del revolucionario Tribunal de Concordia en $1812 .{ }^{64}$ Otra decisión asamblearia fue la ratificación por aclamación de Aráoz en su cargo de gobernador, originalmente designado por el gobierno central. De esta manera, se investía de legitimidad popular a la autoridad del gobernador y se entendía cumplir con el Estatuto que exigía la elección popular de los gobernadores. Esto habla de un voto corporativo y jerárquico que lejos estaba del voto individual que conformaba el horizonte de expectativas del Estatuto Provisional. En este sentido, la Asamblea replicaba el modo de elección de los gobernadores de Salta; Córdoba, Santa Fe y Salta habían sido elegidos popularmente o aprobados por el vecindario, como fue el caso de San Martín en Mendoza. Aunque en esos casos el recurso preferido había sido el de cabildos abiertos (con apoyo popular en el caso de Güemes). Todos ellos nombrados antes de la sanción del Estatuto. El gobernador tucumano originalmente nombrado por el Director Supremo, era "reelegido" por aclamación por la parte del "pueblo", compuesto por "gente decente" y milicianos, que había participado de esa multitudinaria reunión. Así lo hizo saber al gobernador de Córdoba, “Tengo el honor de ofrecerme a VS en el cargo de Gobernador Intendente de esta provincia a que por segunda vez he sido llamado por voto general en Cabildo abierto, celebrado el 30 de junio". ${ }^{65}$ En síntesis, la asamblea, en un mismo acto y por aclamación, anuló lo realizado por el cabildo, confirmó la vigencia del Estatuto, eligió diputados al congreso soberano a reunirse en 1816 e hizo lo propio con el gobernador Bernabé Aráoz. Todo esto alterando el procedimiento

\footnotetext{
${ }^{63}$ Acta del 30 de junio de 1815, en AC..., cit., p. 271.

64 ÁVILA, Julio La ciudad..., cit., p. 68. LEONI PINTO, Ramón Tucumán..., cit., p. 130. GARCÍA, Irene “Tucumán. Letrados y caudillos a partir de 1810", en GARCÍA, Irene y LÓPEZ, Cristina del Carmen (comps.) Representaciones, sociedad y política en los pueblos de la República. Primera mitad del siglo XIX, Instituto de Historia y Pensamiento Argentinos, Facultad de Filosofía y Letras - Universidad Nacional de Tucumán, Tucumán, 2005, pp. 55-109.

65 Oficio de Aráoz al gobernador de Córdoba. 03 de julio de 1815, Archivo de Córdoba, Libro 42, A. 1815, legajo 20. “Tengo el honor de ofrecerme a VS en el cargo de Gobernador Intendente de esta provincia a que por segunda vez he sido llamado por voto general en Cabildo abierto, celebrado el 30 de junio." En MANDELLI, Humberto Constitución de la República del Tucumán. Año 1820, Imprenta de Julio Suárez, Buenos Aires, 1930, p. 18.
} 
propuesto por la normativa en discusión. ${ }^{66}$

La reunión fue calificada por sus críticos como "Asamblea popular", "Junta tumultuaria", 67 "comicio militar y no cívico". ${ }^{68}$ Además dejaron en claro que por detrás de esto, se desarrollaba una lucha facciosa señalando que "los pretendientes a ser tenidos y reconocidos por Diputados de Tucumán, no los quiere la ciudad; pero los quiere el partido que prevaleció con la fuerza y manejos en la gente de esta jurisdicción". ${ }^{69}$ A la vez reclamaban que los tres nombrados el 30 de junio debían subordinarse al ejecutivo "con facultades de deliberar sobre la suerte de aquel Pueblo [de Tucumán] con dependencia al gobierno para que en una sola familia se conserve la Soberanía".$^{70}$

El mismo Aráoz se esforzó por distinguir lo que consideró un "cabildo abierto" o "pueblada"71 de la condición de "tumulto" ante el resto de la comunidad local ausente del Campo de las Carreras y, especialmente, ante los interlocutores externos (Director y gobernadores) dos cosas. El recurso a la acción directa de la multitud, aunque legítimo en el imaginario político de la época, ${ }^{72}$ no era una crítica exclusiva del cabildo o los notables opositores sino que incluía a la propia facción que sostenía al gobernador. Estos preferían "evitar nuevas reuniones siempre peligrosas y perjudiciales", según rezaba la propia acta del 30 de junio. Frente a la imagen de moderación que insistía en sostener Aráoz, la reunión registró, cuando menos, una fuerte discusión entre Nicolás Laguna fue protagonista de un entredicho con Juan Bautista Paz y Pedro Miguel Aráoz del que lamentablemente desconocemos los términos. ${ }^{73}$ Por otra parte, la ciudad toda se vio envuelta en un clima intimidante que alteró la cotidianeidad. Lo cierto es que la facción del gobernador aspiraba a una rápida

\footnotetext{
66 "De las elecciones de los Gobernadores de Provincia", en Estatuto provisional para la dirección y administración del Estado, dado por la Junta de Observación (05 de mayo de 1815), Sección V, Capítulo V, artículo Io.

${ }^{67}$ Diego León de Villafañe a Ambrosio Funes, Tucumán, 25 de enero de 1816, en FURLONG, Guillermo (comp.) "Diego León de Villafañe y sus cartas referentes a la revolución argentina”, en Boletín de la Academia Nacional de la Historia, año XXXVII, núm. XXXI, Buenos Aires, 1960, pp. 181-182.

${ }^{68}$ Nicolás Laguna al Director Supremo, Tucumán 3 de julio de 1815. Citado por BAZÁN, Osvaldo Raúl Historia..., cit., p. 171.

${ }^{69}$ Diego León de Villafañe a Ambrosio Funes, Tucumán, 25 de enero de 1816, en FURLONG, Guillermo (comp.) “Diego León de Villafañe...”, cit., pp. 181-182.

${ }^{70}$ Los firmantes eran Nicolás Laguna; José Ramón Ledesma; José Tomas Alurralde; Domingo García y Manuel Bazán. Oficio de los diputados al Director Supremo. 9 de julio de 1815. Archivo General de la Nación, División Gobierno, Gobierno de Tucumán, 1815. Sala X. 5-10-3.

${ }^{71}$ Cayetano Araoz a José Agustín Molina, Buenos Aires, 18 de julio de 1815, en RODRÍGUEZ, Fray Cayetano Correspondencia..., cit., p. 137

72 HERRERO, Fabián Movimientos de pueblo..., cit.

${ }^{73}$ Expediente sobre "Declaraciones sobre el orden que se supone haberse observado en las actas de la Ciudadela", 07 de julio de 1815, Archivo General de la Nación, Fondos Documentales Congreso Constituyente (1816-19), Sala VII, Legajo 7. Documento 130.
} 
vuelta al "orden", un orden que -según interpretaban- había sido corrompido no por la asamblea, sino por los ocho electos para discutir el Estatuto.

La forma que tomó la asamblea del 30 de junio en el Campo de las Carreras es similar a lo que Fabián Herrero conceptualiza como un "movimiento de pueblo" remitiendo a la experiencia porteña en la década revolucionaria. ${ }^{74}$ En los orígenes hubo una "representación", un recurso tradicional para expresar las demandas del pueblo dirigida al Director Supremo. Congregó fuera de las paredes capitulares un importante número de personas, de diversa condición social, en su mayoría milicianos armados de la "campaña". Al igual que lo que ocurriría en Buenos Aires, en junio de 1816, la iniciativa de una "asamblea popular" fue de quien ejercía el poder ejecutivo (central) para enfrentar al cabildo que proponía elecciones indirectas. Sin embargo, a diferencia del esquema que Herrero plantea para Buenos Aires, en Tucumán el cabildo estaba próximo a actitudes federales mientas el gobernador apostaba por el centralismo. Y en esto incidía menos la distribución de atributos de poder que asignaba el Estatuto a las autoridades residentes en Buenos Aires, que al postulado estatutario que establecía que la legitimidad ahora residía en la soberanía popular. De este modo, las orientaciones políticas fueron bien diferentes en el caso tucumano y el bonaerense de 1816 estudiado por Herrero. El 30 de junio, en Tucumán se sostuvo la adhesión a las autoridades centrales y su representante local, a la normativa por ellas producida, así como se llevó adelante la elección de diputados a un congreso que se presentaba como iniciativa de estas autoridades. En el movimiento bonaerense de junio de 1816 se defendía una posición confederal en oposición al cabildo porteño y la Junta de Observación, cuyas inclinaciones centralistas habían logrado estampar en la normativa de 1815 construyendo un ejecutivo débil (de ahí el rechazo del Estatuto por parte de San Martín). Pero el encuentro tucumano tuvo por fin confirmar al gobernador, y por extensión, la autoridad del gobierno central; no cuestionar o deponer. Su carácter fue resolutivo y esto quedó de manifiesto en el acta que se impuso al cabildo.

Las decisiones tomadas en el Campo de Honor exigieron del concurso de los ausentes en el "Campo de las Carreras". Por ello, acto seguido, la asamblea de la Ciudadela, "invitó" a un cabildo abierto en la tarde de ese mismo 30 de junio con el fin de que las corporaciones sumaran "sus votos con estos libremente y sin coacción".${ }^{75}$ Por ello se convocó apresuradamente a un cabildo abierto. De esta manera se recreaba la visión tradicional de "pueblo" en tanto comunidad que reconocía una sola voz corporativa. Una sola voz en la que la institución capitular ya no podía reclamar su representación de modo excluyente.

\footnotetext{
74 HERRERO, Fabián Movimientos de Pueblo..., cit.

${ }^{75}$ Acta del 30 de junio de 1815, en AC..., cit., p. 271.
} 
Los participantes no eran ya la "parte más sana" de la ciudad sino simplemente los que no había participado de la reunión de la Ciudadela. Sin embargo, quienes debatieron entre las tradicionales paredes capitulares fueron mencionados como los "literatos", los "ilustrados" por aquellos que se encontraban rodeando la casa capitular. ${ }^{76}$ De hecho muchos ostentaban títulos de doctor. La voz cantante en ese cabildo abierto, confuso para muchos de sus participantes, fue la de uno de los electos diputados en la Asamblea, José Agustín Molina. Este rechazó la anulación de las elecciones del 22, renunció a su nombramiento como diputado e insistió en la invalidez de la elección de los diputados al congreso del año siguiente ya que no respetaban lo establecido por el Estatuto de mayo de 1815. Respecto de la ratificación del Estatuto y del Director así como en la relación de unión con Buenos Aires hasta la realización del congreso, hubo unanimidad con lo decidido en la Asamblea del Campo de Honor. La presencia del gobernador en el recinto capitular persuadió a los presentes en su decisión de ratificar lo actuado horas antes. ${ }^{77}$ Claro está que, el gobernador, que como ya se dijo ostentaba títulos militares, estaba acompañado por los oficiales del Regimiento de Dragones de Caballería reglada. Todos portaban armas. En tanto, afuera del recinto capitular se encontraba reunido el "pueblo" que se había trasladado desde las afueras de la ciudad hacia la plaza.

La partida pareció ganada por el gobernador, quien habría sido su autor intelectual, ausente en la Ciudadela. ${ }^{78}$ El juramento al Estatuto sancionado por la asamblea de la Ciudadela el 30 de junio, fue previsto se realizara el 6 de julio "por todas las autoridades, Jefes y cuerpos militares, y los demás oficios que se verificó en dicha capital"79 atendiendo a las especificaciones de la décima providencia del capítulo final del Estatuto. Sin embargo, no existen documentos que den cuenta de su concreción. Tampoco las elecciones capitulares de 1815 pusieron en práctica lo pretendido por el Estatuto. El $1^{\underline{0}}$ de octubre de ese año, como ocurría desde 1805, los capitulares nombraron a sus sucesores -por cooptación- no sin previa y ardua discusión. En noviembre, Ignacio Álvarez Thomas aprobaba las elecciones capitulares aunque observaba algunas irregularidades, entre las que mencionaba la repetición en los cargos de varios capitulares. Simultáneamente, concedía a los gobernadores intendentes la facultad para aprobar las elecciones capitulares con aplicación "en los años siguientes". ${ }^{80}$ Sin embargo, el gobernador Aráoz se ocupó de confirmar las

\footnotetext{
${ }^{76}$ Expediente sobre "Declaraciones sobre el orden que se supone haberse observado en las actas de la Ciudadela", 07 de julio de 1815, Archivo General de la Nación, Fondos Documentales Congreso Constituyente (1816-19), Sala VII, Legajo 7. Documento 130.

${ }_{77}$ Acta del 30 de junio de 1815, en AC..., cit., pp. 274-278.

${ }^{78}$ LIZONDO BORDA, Manuel Historia..., cit. y PÁEZ DE LA TORRE, Carlos Historia ..., cit.

${ }^{79}$ Acta del 04 de julio de 1815, AC..., cit., pp. 278-279.

80 Transcripto por Bernabé Aráoz de resolución del Director Supremo del 03 de noviembre de 1815. Noviembre 15 de 1815. Archivo Histórico de Tucumán, Sección Administrativa, Vol. 24. f. 275.
} 
elecciones en ese mismo año. Por su parte, mediados de 1816, la corporación capitular solicitaba al Director Supremo, la reforma de la Superior Providencia del 3 de noviembre de 1815 que autorizaba a los gobernadores a aprobar las elecciones de los cabildos. ${ }^{81}$ Las primeras elecciones populares de capitulares se realizaron en Tucumán recién en 1818, a diferencia de lo ocurrido en otros pueblos como el de Buenos Aires.

El Director Supremo había sido informado del conflicto local por sus protagonistas. Limitado en su accionar por el control de cabildo porteño y la Junta de Observación así como por la presión de Artigas en el Litoral y de Güemes desde Salta, Álvarez Thomas no encontraba oportuno tomar una decisión que alterara el equilibrio inestable en que vivía. Podría decirse que en actitud respetuosa de los derechos de los pueblos, derivó la resolución de las diferencias al Congreso a reunirse el siguiente año en la misma ciudad de Tucumán, mientras reconvenía extraoficialmente a Aráoz por la acción que reconocía haber liderado. Tal vez por ese motivo, Aráoz no solo se comunicó de manera oficial con el Director Supremo, sino también con otros gobernadores. Además de la comunicación con el gobernador de Córdoba reafirmando su condición de gobernante electo popularmente, también escribió a San Martín sosteniendo que la asamblea había otorgado a los diputados nombrados la calidad de "representar los derechos de la ciudad en el Congreso". ${ }^{82}$

Como en el caso de Buenos Aires en 1816, el resultado de la contienda no fue del todo claro. A corto plazo, el vencedor fue el gobernador Aráoz y así lo vio la historiografía. A largo plazo, la aprobación del Estatuto por una parte de la comunidad tucumana entera no fue uno de sus logros como lo hizo saber una representación capitular presentada en marzo de 1816 al Congreso General Constituyente. ${ }^{83}$ Sin embargo, no resultaría fácil dirimir esta cuestión para el Congreso, ya que varias elecciones más y un reglamento especial para Tucumán serían necesarios antes de resolver el conflicto entre cabildo y gobernador, en lo relativo a la selección de representantes por Tucumán. ${ }^{84}$

\section{Epílogo. Usos de la noción de "pueblo" y alternativas autonómicas}

Este escrito pone el acento en el análisis de la coyuntura, atendiendo a los

\footnotetext{
${ }^{81}$ Acta de Julio de 1816, AC..., cit., p. 340.

82 Oficio de Aráoz a San Martín, Tucumán 30 de junio de 1815. Citado en VERDÓ, Geneviève "El precio...", cit., p. 400.

${ }^{83}$ Representación del Cabildo de Tucumán al Congreso, 26 de marzo de 1816, Archivo General de la Nación, Fondos Documentales Congreso Constituyente (1816-19), Sala VII, Legajo 2. Actas y poderes de diputados, Documento 59.

${ }^{84}$ LUPIAÑEZ, Gabriela Paula "Las elecciones de diputados por Tucumán al Congreso General Constituyente de 1816", en X Jornadas La Generación del Centenario y su proyección en el Noroeste argentino. Desde el Centenario hacia una historia integral del NOA. 1900-1950, Fundación Miguel Lillo/Centro Cultural Rougés, San Miguel de Tucumán, en prensa.
} 
tiempos cortos de la política a escala local. Una dimensión que se desarrolló a partir de 1810, con la retroversión de la soberanía en los pueblos; el poder se volvió disputable y la ciudad adquirió una dimensión política de la que había carecido hasta el momento. La aprobación de un Estatuto que establecía que los fundamentos del poder residían en la soberanía popular a la vez que declinaba la definición del sujeto soberano en los pueblos, replicó la disputa sobre el sujeto de la soberanía al interior del pueblo de Tucumán con ímpetus desconocidos hasta el momento en la comunidad local.

En junio de 1815, una facción que encontraba eco en el cabildo tucumano, reacio a la aceptación incondicional del Estatuto, decidió someterlo a consulta popular. El cabildo tomaba un camino desconocido hasta el momento, si se lo juzga por las decisiones asumidas ante iniciativas del gobierno central entre 1806 y 1816. De este modo, el representante del "pueblo", según la tradicional constitución, ejercía la prerrogativa de velar por los "derechos del pueblo". Pero el 30 de junio, la facción que apoyaba al gobernador clausuraba la posibilidad de discusión con un "movimiento de pueblo".

El enfrentamiento entre cabildo y gobernador tucumanos remitía a la cuestión de quién se erigía en portavoz legítimo del "pueblo". Un pueblo que había que recrear, hacer visible. El cabildo movilizó a la comunidad para que se expresara a través de elecciones indirectas, procedimiento impuesto al calor de la revolución y confirmado por el Estatuto del 15. De este modo, los notables intentaban canalizar la participación de un público cada vez más amplio a la vez que evitar posibles disturbios. Si bien las elecciones indirectas definían un "pueblo" cuantitativamente más inclusivo que en tiempos previos, este era un sujeto decididamente mucho más selecto y reducido que aquel invocado en la asamblea reunida posteriormente en apoyo del gobernador.

Al gobernador Aráoz, entonces, no le quedó otra alternativa que apelar a un acto que visibilizara la "voluntad popular" para definir la pulseada. Lo hizo apelando a los "sagrados derechos de todo ciudadano" en una reunión con gran participación de la campaña. Adornado de atributos de poder obtenidos de la guerra y la revolución; esta autoridad nueva en la ciudad de Tucumán, era producto de la política centralista de creación de intendencias en el contexto de guerra en todos los frentes. La pérdida de control del gobierno central sobre el territorio en 1815, redundó en la pérdida de legitimidad de la condición de gobernador de Aráoz. En un acto desesperado -que prometió no repetir-, Aráoz procuró reafirmar su poder en el Campo de las Carreras. La imagen de un "pueblo" en ejercicio directo de la soberanía se materializaba en la imposición por el número, por la calidad de algunos notables presentes y por la fuerza de las armas. Las decisiones del Campo de las Carreras fueron coactivamente ratificadas en un "cabildo abierto" obligado a reunirse el mismo día para representar a la parte que no concurrió a asamblea. De este modo, la voz del "pueblo" de Tucumán, volvía a ser una sola bajo la iniciativa del gobernador. 
Estos usos de la noción de "pueblo" incluían modos alternativos de entender la relación entre el pueblo de Tucumán y el gobierno revolucionario. Contrariamente a lo que la historiografía estableció oportunamente, el cabildo tucumano y otras corporaciones locales no juraron el Estatuto Provisional, a diferencia de la facción liderada por el gobernador presente en el Campo de las Carreras. Sin embargo, esto no fue óbice para reconocer las autoridades centrales hasta tanto se reuniera el nuevo congreso prometido. De este modo, la relación armónica entre autoridades centrales y la ciudad descripta por la historiografía, no fue la única discutida en la ciudad devenida en capital de la provincia de Tucumán. En el abanico de opciones que se presentaban en la relación con el gobierno central, la resultante de la confrontación de fuerzas antes que producto de posiciones ideológicas definidas- no era del todo clara en el seno de la comunidad local. Lo único firme fue el descarte de plano de la opción de la independencia total respecto del gobierno central. Así, el gobernador (no ya el cabildo) se inclinaba por una relación de franca alineación con el gobierno central y sus iniciativas, sosteniendo la tradicional alianza de la comunidad tucumana con los gobiernos centrales. La confederación era una posibilidad para una minoría mientras el cabildo, cuestionado en su rol tradicional de portavoz de la comunidad local, se hacía eco del reclamo de los "derechos del pueblo". De ahí que ante este escenario, las palabras de Fray Cayetano Rodríguez al inicio de este trabajo, adquirieran una relevancia insospechada.

En síntesis, los sentidos que pudo adquirir la noción de "pueblo" en la comunidad tucumana, fueron efecto de luchas particulares entre cabildo y gobernador. En Tucumán procuraron erigirse en portavoces excluyentes del "pueblo", sobre la base de apelación a legitimidades opuestas (una tradicional, la otra revolucionaria), y el sostenimiento de versiones propias respecto de la definición del sujeto soberano y los modos de ejercicio de ese poder popular. Sin embargo, en ambos casos las versiones continuaban remitiendo a un sujeto corporativo y jerárquico a la vez que dejaba de entenderse como una entidad cuya existencia se debía a la figura del rey en un contexto en que la amenaza de una expedición militar enviada por Fernando VII a reprimir la insurgencia estaba muy presente.

El Corte, Yerba Buena, 3 de julio de 2016 